\title{
DECADENCIA Y APOGEO DEL ESPACIO. DIMENSIONES CULIURALES DEL CAMBIO SOCIOECONÓMICO EN UN CASO DE RENOVACIÓN URBANA EN COLOMBIA*
}

\author{
Gregorio Hernández Pulgarín** \\ Universidad de Caldas - Colombia
}

Resumen: En este artículo me propongo analizar la valoración simbólica de un espacio urbano a lo largo de un periodo de transformaciones económicas en Pereira, Colombia. Abordo la transición entre un momento en el que la plaza de mercado sintetizaba sentimientos y significados de adscripción favorables gracias a su vínculo con la economía cafetera, y otro en el que esta actividad económica devino intrascendente y la valoración simbólica negativa de este espacio ahora "obsoleto" justificó su demolición y la construcción de un complejo urbano de vocación comercial "moderna". Este estudio, implicó la observación de dicho espacio durante varios periodos, así como la realización de entrevistas a individuos claves en la planeación urbana local y la consulta de fuentes secundarias. El empleo de la noción de estructura de sentimiento me permitió explicar la manera como se codifican culturalmente algunos fenómenos económicos que inciden en las transformaciones espaciales.

Palabras clave: economía, espacio, estructuras de sentimiento, renovación urbana.

Abstract: This article looks for the analysis of the symbolic value of an urban area during a period of economic changes in Pereira, Colombia. It studies the transition between a time when the marketplace synthesized favorable feelings and meanings thanks to the coffee economy, and other in which this economic activity became

\footnotetext{
* La investigación que soporta este artículo se realizó en el marco del laboratorio de investigación Lab’Urba de la Université Paris-Est en Francia y del Grupo de Investigación Territorialidades de la Universidad de Caldas en Colombia. Para su realización fue esencial el soporte intelectual de Jérôme Monnet y de Anne Jarrigeon, así con el apoyo de Sofía Lara. El aporte financiero ha sido del Departamento Nacional de Ciencia, Tecnología e Innovación de Colombia- Colciencias y de la Universidad de Caldas. El tema ha sido debatido en varios escenarios de la Red Internacional de Estudios sobre Territorio y Cultura-RETEC.

** Contacto: gregorio.hernandez@ucaldas.edu.co.
} 
insignificant and the symbolic value of this space "obsolete" became negative and that justified their demolition and the construction of a "modern" commercial urban complex. This study involved the observation of this space for different periods, as well as conducting interviews with the politicians and the experts in the local urban planning and reviewing secondary sources. The use of the notion of structures of feeling let me explains how the cultural codification of some economic phenomena can affect the spatial transformations.

Keywords: economy, space, structures of feeling, urban renewal.

\section{Introducción}

Pereira, una ciudad intermedia de Colombia, fue sacudida por un sismo de magnitud 6,4 en la escala Richter en enero de 1999. El centro de la ciudad fue el sector más afectado, específicamente la plaza de mercado central y sus alrededores, conocido localmente como la galería. El antiguo edificio donde se concentraba la actividad del mercado central continuó en pie, aunque cerrado, después de los efectos del sismo sobre su estructura y aspecto. A pesar de su cierre, el sector seguía presentando una vida comercial rica, sobre todo en intercambios con habitantes de las áreas rurales del municipio.

El edificio fue demolido seis meses después del sismo, en el marco de una serie de iniciativas que buscaban la renovación de este sector céntrico de la ciudad. Las decisiones sobre qué hacer con este espacio, se orientaron hacia la realización un proyecto de desarrollo urbanístico que tenía por objeto la sustitución de un lugar asociado particularmente a una forma de vida rural y cargado de estigma por el tipo de personas que lo frecuentaban y por las prácticas que allí tenían lugar. En su lugar se construyó un conjunto de edificios, de centros de comercio y de espacio público que buscaban "refundar” y "modernizar" la ciudad. Al cabo de menos de una década, un espacio representativo de una economía rural que lograba sintetizar valores y sentimientos identitarios y de pertenencia, fue arrasado para darle lugar a una trama urbana revestida de un halo de "modernidad" que se materializaba en nuevas formas de comercio y consumo, también portadoras de significado colectivo.

En el marco de mi investigación doctoral pretendo interpretar la codificación cultural de las transformaciones económicas y sociales de la ciudad, a través de un análisis de lo que acontece en el espacio urbano. En este artículo derivado de esta investigación, busco comprender la transición en los 
significados adquiridos socialmente por un espacio que adopta diferentes prácticas económicas, inspirado en el concepto de "estructura de sentimiento”. Este concepto le fue útil a R. Williams (2001) para analizar las representaciones sobre el campo y la ciudad en Inglaterra, en un periodo histórico en el que el capitalismo imprime su sello ideológico, simbólico, representacional sobre dichas realidades y específicamente sobre la manera de percibirlas y de sentirlas. El caso colombiano que analizo abarca una dimensión temporal menor a la abordada por Williams y presenta, como es obvio, una serie de fenómenos que no se corresponden con hallado por éste en Inglaterra: otra expresión del capitalismo o de la ciudad, por ejemplo.

Mi aproximación se soporta en varias temporadas de terreno correspondientes a diferentes iniciativas de investigación desde 2004 hasta 2014. En los apartados siguientes pretendo analizar la transición de un espacio urbano que se transforma, siguiendo por una parte una serie de cambios económicos gestados a nivel local y global que son codificados culturalmente. Dicha codificación remite a las líneas “ideológicas y utópicas” del desarrollo (Lins Ribeiro, 2007, p. 183), del progreso y de la modernización, que se convierten en cartas de navegación para las élites que gobiernan la ciudad, pero que no son indiferentes a otras capas de la población que reproducen los principios de una forma de capitalismo en la que se enaltece la búsqueda de progreso individual.

\section{Una entrada antropológica a las transformaciones urbanísticas}

Antes de iniciar con el análisis, valdría la pena precisar que las operaciones de urbanismo donde se concretan las transformaciones de los espacios urbanos se basan en ideologías, discursos y representaciones que tienden a cimentar la idea de que dicha operación, aproximará a la ciudad o a una parte de ella a una especie de "ciudad ideal" (Monnet, 1993, p. 185). Las transformaciones urbanas se sustentan en ideologías de progreso o de desarrollo, que siguen la retórica del capitalismo como ha sido mostrado por diversos autores desde la antropología (Herzfeld, 1993, 2009; Low, 2009; Okongwu, 2000; Wedel; Feldman, 2005).

Una corriente de estudios urbanos críticos propone un análisis de lo que suele llamarse ideologías neoliberales en la concepción y gobierno de las ciudades actuales. Algunos de estos estudios se centran en la privatización de la ciudad (Hackworth, 2006; Harvey, 1989; Low, 2009), en la concepción 
cosmética del espacio (Esteban, 2007; Van Criekingen, 2008), en la injusticia espacial y en las nuevas formas de gobierno urbano (Béal; Rousseau, 2008; Harvey, 1989; Peck; Theodore; Brenner, 2009). A diferencia de muchas de estas aproximaciones, mi propuesta tiene que ver con el análisis de la transformación de un espacio de la ciudad y de la ciudad misma, en función de las estructuras de sentimiento vigentes, y parte además de un postulado próximo a la antropología económica de corte sustantivista: en las sociedades occidentales la economía hace parte del universo sociocultural (Polanyi, 1983). Desde esta perspectiva el capitalismo es un sistema cultural (Sahlins, 1997), un conjunto de símbolos y valores (Bloch, 1994; Fassin; Eideliman, 2012; Graeber, 2001), de discursos (Escobar, 2010), de dispositivos ideológicos (Dumont, 1978; Lins Ribeiro, 2007) que condicionan las maneras de pensar y la actuar de los individuos y de las instituciones.

Los postulados de la antropología económica sostenidos por estos autores, son disímiles. Un elemento común a estas aproximaciones que inspira mi abordaje, es considerar que las actividades económicas que tienen lugar en un espacio y las formas de valorar esas actividades y al espacio mismo pueden analizarse desde una perspectiva en la que se destaque la construcción de sentido.

En este marco, las acciones políticas ejecutadas para transformar un espacio en las ciudades actuales, además de verse como una instrumentalización de los principios del capitalismo, pueden entenderse como una forma de “rehabilitación simbólica del espacio urbano" (Althabe, 1993, p. 7). En ésta confluyen diferentes maneras de significar la "modernización”, “el progreso" o el "desarrollo" de la ciudad, unas veces promovidas por aquellos que conciben y ejecutan las políticas públicas y otras respondiendo a fenómenos sociales que no necesariamente obedecen a la instrumentalización de los representantes del Estado. Las manifestaciones del deseo de cambio, se inscriben en estructuras de sentimiento, que proyectadas en el espacio, definen un modelo de ciudad. En América Latina, ese modelo de ciudad tiende a enaltecer el asiento en el espacio urbano de actividades económicas del sector terciario de la economía. Lo anterior hace recurrente una rehabilitación física y simbólica en la que se privilegia la presencia de malls o de edificios que acogen la realización actividades de servicios, los cuales favorecen la producción y reproducción de formas de vida asociadas a los valores del consumo y de la posesión ostentosa de bienes. 


\section{Configuración y degradación de un espacio urbano}

Los relatos de historiadores y otros escritores locales coinciden en describir la galería como un espacio caracterizado por una dinámica actividad social cotidiana, en donde confluían productores, comerciantes y clientes de las zonas urbanas y rurales del municipio. Esta configuración del espacio en torno a la plaza de mercado, existía desde 1923, año de la fundación de la plaza. En ese período las ciudades colombianas presentaban una relación estrecha con las zonas y actividades rurales, y los mercados locales eran centros de distribución para la producción agrícola local y regional, espacios de configuración de vínculos sociales y de articulación de las zonas urbanas y rurales (Castro Carvajal, 1994). Por estas razones los mercados locales constituían zonas de importante actividad urbana, representada por una alta densidad y movilidad comercial (Baquero, 2011).

Las actividades de mercado de Pereira antes de 1923 se celebraban en la plaza principal de la ciudad, la Plaza Victoria, ubicada donde hoy se encuentra la plaza central de esta ciudad. Para la construcción de la plaza de mercado en el año 1923 el gobierno local concedió un terreno de un bloque. ${ }^{1}$ El edificio en principio ocupaba la mitad del espacio cedido y ganaría el resto entre 1955 y 1957, cuando se construyó la parte restante (Ramírez; Tarazona, 2007).

Tras la renovación de la galería en 1957 y gracias al desarrollo de la economía del café hasta 1989, las actividades comerciales y sociales se dinamizaron en este espacio urbano. Durante este periodo seguían acudiendo los campesinos de las fincas cercanas, aunque más a abastecerse de bienes que a vender productos agrícolas, dado que la mayoría de ellos se habían dedicado al monocultivo de café. Además de los intercambios de víveres, los campesinos adquirían otros bienes y accedían a servicios y actividades en los numerosos bares y burdeles de la zona.

El crecimiento de las actividades y la expansión del sector, que hacia 1957 ocupaba un área de aproximadamente un bloque de calles y que hacia los años ochenta contaba con cerca de treinta bloques, se debe al desarrollo ligado a la economía cafetera y a los saldos migratorios positivos de la época. Entre

1 El bloque es conocido localmente como una manzana, es decir, una cuadricula de aproximadamente 90 metros de lado que hace parte del trazado ortogonal que predomina en Pereira.

Horizontes Antropológicos, Porto Alegre, ano 22, n. 45, p. 249-278, jan./jun. 2016 
1951 y 1993, la ciudad pasó de 115.342 a 401.909 habitantes. La explicación de los saldos migratorios recae en el desarrollo económico y urbano ya advertido en torno al café (Arango, 2000; Mejía, 2011; Rivera, 2013), pero también a un fenómeno representativo en el caso del crecimiento urbano en Colombia, la migración forzada por la violencia (Aprile-Gniset, 1992). ${ }^{2}$

La ciudad de Pereira fue el epicentro de la zona cafetera, lo que creó una fuerte dependencia económica a esta actividad. Incluso otros sectores de la economía se beneficiaron de los capitales asociados al café y aportaron al proyecto de “modernización de la economía local” (Rivera, 2013, p. 335), basado como en toda América Latina, entre 1930-1990, en el desarrollo de la industria en el caso local, incluyendo alimentos y textiles.

Esta economía urbana dependiente del café se reflejaba en la configuración espacial, social y comercial de la galería. La consolidación de varios locales comerciales alrededor del ocio (bares, burdeles), los hoteles, el transporte y la venta de alimentos se basaba en la demanda asociada a la producción agrícola, sobre todo a la constituida por la amplia fuerza de trabajo necesaria para el funcionamiento de la economía cafetera.

Lo anterior se reflejó en la consolidación del sector de la galería como la mayor estructura comercial dentro de la configuración espacial de la ciudad entre los años 1950 y 1990. El edificio central, lugar fundador, fungía como epicentro de actividades que vitalizaban el sector. Las casas patrimoniales situadas alrededor del edificio fueron paulatinamente transformadas en espacios de pequeños apartamentos precarios, inquilinatos, en locales comerciales y en hoteles. Estos usos urbanos fueron expandiéndose, logrando abarcar un espacio significativo del centro de la ciudad. La otra parte del centro se fue desarrollando en torno a una economía terciaria, sobre todo de servicios financieros y comercio para la población urbana.

Estas actividades ocupaban una extensión de cerca de 9 hectáreas desde 1980, en el centro de la ciudad, sin embargo, el área de influencia era más

\footnotetext{
2 En el periodo intercensal que comprende los años 1951 y 1964, reconocido escenario de la Violencia política bipartidista, la tasa de crecimiento de Pereira fue del 37\% (Rivera, 2013). Dicha tasa se redujo al 20,05\% en el intervalo 1964-1973. En periodos posteriores la tasa de crecimiento siguió presentando un incremento superior al 10\%. Aunque el efecto de la violencia política y aquella ligada al narcotráfico de la última década de siglo XX y de comienzos del XXI, no marcó a Pereira como una ciudad privilegiada para recibir población desplazada, se estima que una parte considerable de las personas que sumaban a las cifras demográficas tuvo como principal razón de desplazamiento el conflicto armado (Mejía, 2011).
}

Horizontes Antropológicos, Porto Alegre, ano 22, n. 45, p. 249-278, jan./jun. 2016 
extensa (Rojas et al., 2000). Hasta finales de los años ochenta, el centro y la galería en su conjunto concentraban las funciones de intercambio, de comunicación simbólica y de poder que justificaban su jerarquía como una centralidad urbana (Monnet, 2000). Pero más allá de esto, en virtud de la magnitud de las relaciones sociales, es decir, de las relaciones simbólicas que tenían lugar en el sector de la plaza de mercado y del hecho de que allí se ponían en juego diariamente intercambios vinculados con la economía cafetera, a la galería se le conferían atributos significativos particulares en tanto que espacio urbano. La economía del café constituía un referente simbólico clave para esta ciudad, dada su localización en el epicentro de la "región del café” y su participación en diferentes actividades relativas a este sector de la economía. Al margen de que labores como la producción o el procesamiento del café no tuvieran lugar en la galería, allí sí existían otras prácticas económicas que cumplían la función significativa de comunicar sobre las bondades de una caficultora en bonanza.

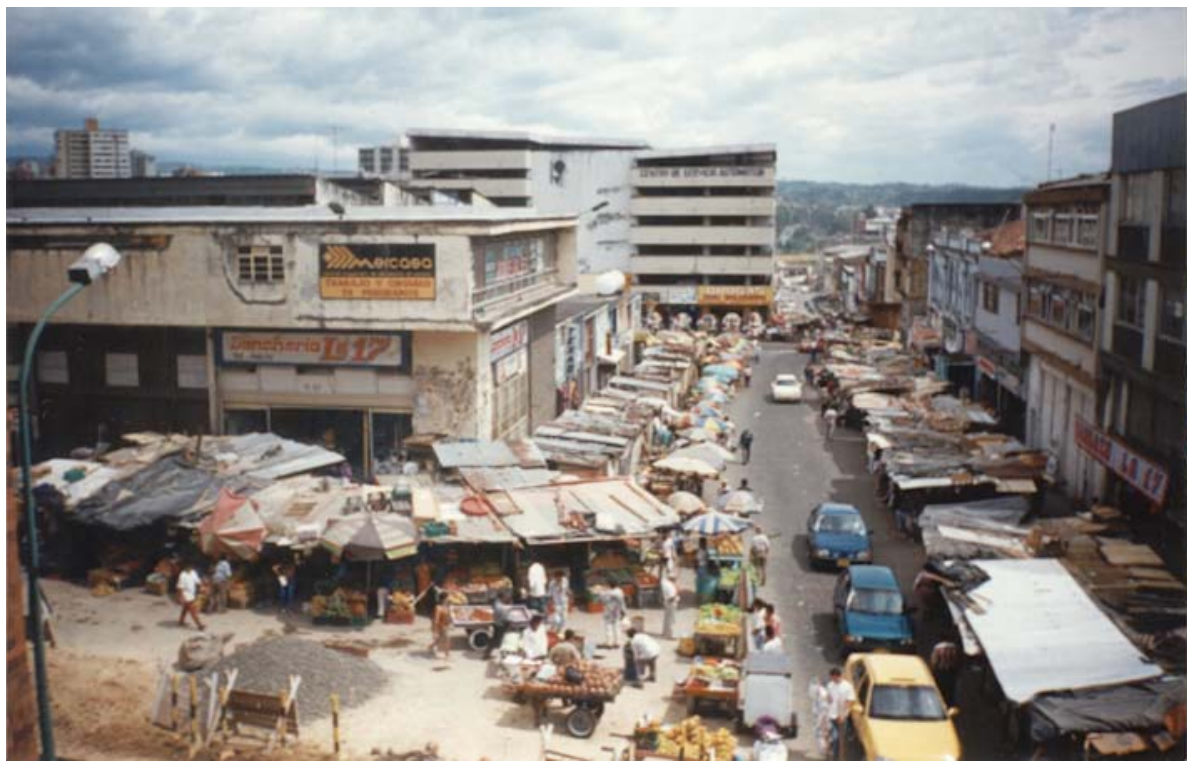

Figura 1. La galería en los años 1990 (fuente: Alcaldía de Pereira). 
El papel simbólico de la economía cafetera en relación con el lugar de la galería en la jerarquía de los espacios urbanos en Pereira, se define en términos del "sistema de valores que permite 'medir la condición' de centralidad de [este] lugar en un orden simbólico” (Monnet, 2000, p. 403, traducción mía). En este orden simbólico urbano, las prácticas asociadas con la caficultura, no solamente eran importantes porque regulaban la vida económica de la ciudad y el país, o porque cumplían un rol clave en la configuración de los poderes locales, sino porque se habían convertido en una fuente de sentimientos de pertenencia socio-cultural, de pertenencia territorial y en general en un referente de la construcción simbólica e ideológica de la "identidad cafetera nacional” (Tocancipá, 2010, p. 115).

Puede plantearse entonces que en la galería se materializan las funciones que según De la Pradelle (1996) hacen de un mercado el objeto legítimo de la antropología: la presencia de los temas sociales y de identidad, y la manipulación de los significados. La importancia concedida al café en la construcción de la identidad regional y la ciudad ha sido objeto de varios estudios (Hernández Pulgarín, 2006; Tocancipá, 2010). Estas investigaciones coinciden en evidenciar el valor de este sistema productivo en tanto que símbolo distintivo, suficientemente relevante para asignar al espacio de los intercambios comerciales entre los actores del café, un lugar predominante en las representaciones que gobernaban la jerarquía del espacio urbano local.

La galería, a pesar de su relevancia simbólica, comenzó a ser descrita como un lugar peligroso y marginal, más que como un lugar central desde la década de 1980. A partir de la década de 1990, este sector atraviesa una crisis que marcó un punto de inflexión para su desaparición, para la transformación del centro de la ciudad y para la adopción de nuevos referentes simbólicos que sustentaran la nueva forma urbana. La degradación física de este espacio central, el desarrollo creciente de actividades asociadas a la ilegalidad y la pretensión de transformar la forma de acceder a una cierta idea de modernidad, constituyeron maneras de cuestionar las cualidades simbólicas atribuidas a este espacio.

\section{La devaluación simbólica de un espacio}

En los años 1980 la galería empezaría a representarse contradictoriamente, por un lado como un espacio importante por sus intercambios y por estar

Horizontes Antropológicos, Porto Alegre, ano 22, n. 45, p. 249-278, jan./jun. 2016 
asociado a los referentes simbólicos del café, y por otra parte como un lugar deteriorado, sucio y un poco peligroso. Lo anterior, ocurría en parte debido a su dinámica rural, que constituía un lugar no totalmente representativo de los modos de vida urbanos, ni de la configuración espacial de una ciudad "moderna".

En ese tiempo las aceras acogían a cientos de vendedores ambulantes, prostitutas, indigentes y rebuscadores, personas que obtenían su sustento en cualquier tipo de actividad, sin reparar en sus límites morales y legales. Sus calles experimentaban problemas de movilidad como consecuencia del comercio de calle, del estacionamiento caótico de los vehículos provenientes de las zonas rurales, de las carrozas jaladas por caballos o por hombres que transportaban mercancías, o de los insólitos mercados de las pulgas, que en su mayoría desplegaban productos robados o recuperados de la basura.

Además de las actividades legales, indeseables por su marginalidad, existían allí actividades ilícitas como el tráfico y consumo de drogas, la prostitución infantil, el robo, la venta de bienes robados y el homicidio. El flujo de las actividades ilegales hacia el centro de la ciudad de los indigentes que habitaban allí y de otras personas que presentaban una apariencia asociada a la ruralidad, se hizo cotidiano. Defensores del centro de la ciudad, un espacio alejado de la estética y del tipo de economía rural, empezaron a manifestar su molestia por estos flujos y por la contigüidad de la galería, y clamaban soluciones a la administración municipal.

Así las cosas, el lugar que simbolizaba el crecimiento económico, "el espíritu de un pueblo”, de una ciudad en el corazón del país del café, se había convertido en indeseable. Una de las razones para esto, la degradación del espacio físico percibida, es documentada incluso como un problema desde la década de 1950, de acuerdo con la Oficina de Planificación del Municipio (Pereira, 2002). En virtud de dicha percepción se propusieron algunos proyectos de renovación urbana desde 1966 que sufrieron la suerte de otras propuestas de la municipalidad y de organismos competentes formuladas en 1984, 1992, 1995 y 1997: no se concretaron debido a problemas con las fuentes de financiación, los intereses de los políticos locales, los problemas con los instrumentos de planificación que regulan este tipo de operaciones urbanas, la oposición de los comerciantes del mercado y los conflictos sociales con las poblaciones sensibles que allí se asentaban (Giraldo, 2003; Ortíz, 2012; Vallejo, 2010). 
En 1995 un terremoto causó daños en algunos edificios de la galería, lo que produjo la demolición de muchos de ellos. Algunos espacios “vacíos” dejados por los edificios demolidos o dañados en sus estructuras, fueron apropiados ilegalmente por personas que realizaban allí actividades marginalizadas que exacerbaron la mala reputación del sector.

En este periodo las actividades ilegales de la economía informal coexistían con una economía formal decadente. La economía local comenzó un descenso significativo debido a la ruptura del Acuerdo Internacional del Café de 1989 y como resultado del tipo de apertura económica adoptada por el Gobierno de la República entre 1990 y 1994. La ruptura del acuerdo tuvo como consecuencia inmediata la caída de los precios internacionales del café colombiano. Entre los principales efectos locales se destaca el empobrecimiento de los productores propietarios y la pauperización de un gran número de individuos que servían de mano de obra de la caficultura (Arango, 2000; Gaviria; Sierra, 2006). El impacto también fue significativo para otras actividades tributarias de la economía del café que se ubicaban en la galería: notablemente la provisión de herramientas, de alimentos y de otros productos comerciales, y la prestación de servicios de ocio a los agricultores.

Por otra parte, la economía local estaba sufriendo las consecuencias de la apertura económica que afectó principalmente a las industrias que desde ese momento tenían que competir por los mercados nacionales con las industrias extranjeras en situación muy desventajosa debido a la caída de las restricciones y a la importación bienes (Lotero Contreras, 1998; Montoya, 2013). Esto repercutió en los índices económicos y transformó las percepciones sobre la ciudad. En términos económicos, la tasa de crecimiento de la economía según el PIB se había resentido: en 1998 era apenas del 1,8\%, cuando en 1990 era del 4,3\%; mientras que el desempleo había aumentado, pasando de 10,4\% a 14,8\% en el mismo período (Rivera, 2013). Es probable que las cifras de crecimiento de la población entre los censos de 1993 y de 2005, que mostraban un aumento de la población urbana del 10\%, mientras que en periodos intercensales anteriores mostraban un incremento cercano al 30\%, reflejen un cambio en la percepción sobre las nuevas condiciones de la ciudad.

En el período más agudo de la crisis del café entre los años 1989 y 2004 (Tocancipá, 2010), la situación económica de la ciudad, resultado de las 
políticas económicas nacionales y del terremoto de 1995, ayudaron a transformar las condiciones socio-económicas de la galería. Estas limitaciones económicas contaron con un correlato en la valoración simbólica asignada a este espacio, esta valoración que se tornó decididamente negativa, influyó para que sectores privilegiados de la ciudad fueran menos tolerantes frente a la degradación física del espacio de la galería que se percibía desde tiempo atrás.

En virtud de lo anterior se entiende por qué funcionarios de la administración municipal argumentaban la necesidad de rehabilitar esta zona. Dicha voluntad, se expresaba en los proyectos de renovación urbana presentados en la década de 1990. Otro ámbito donde se puede percibir la devaluación simbólica experimentada por este espacio aparece en los diarios locales de la época. En una columna del periódico La Tarde del 23 de junio de 1996, se decía:

La galería central de Pereira nació como un centro de provisión de víveres para una población normal, tranquila y progresiva. Con el transcurrir del tiempo, el lugar conformado por 45 manzanas sucumbió en una zona de poco desarrollo e indolencia social. La galería se fue transformando en un centro de conflicto donde la invasión, drogas, prostitución, inquilinatos, invasión del espacio público, delincuencia, abandono y explotación, se transformaron en los principales elementos diarios.

Este tipo de relatos se radicalizaron aún más después de la transformación experimentada por la galería a causa del sismo 1999, referenciado al principio de este artículo. Como ya había ocurrido con el terremoto de 1995, personas marginalizadas y estigmatizadas se apropiaron de las estructuras averiadas y casi deshabitadas, una situación que tuvo sus efectos sobre la pérdida del valor económico del suelo (García; Marín, 2012) y potenció las representaciones de este espacio en torno al miedo, a la violencia, la suciedad y la ilegalidad.

En otro periódico local influyente, el Diario del Otún del 10 de abril de 1999, se apelaba a una analogía organicista para afirmar que la galería era un “cáncer" en la ciudad, centrándose en la influencia nefasta de galería en los órganos vecinos (el centro) y en el sistema en general (la ciudad). Esta idea fue compartida por algunos representantes de la administración municipal que encontraban en el daño de los edificios, sobre todo en el de la plaza de mercado, la oportunidad de acabar con este espacio "patológico” y replantear el futuro de la ciudad. 


\section{El triunfo del progreso}

El edificio central de la plaza de mercado, el epicentro de la galería, a pesar de las consecuencias del sismo de 1999, estaba aún en pie. El Taller de planificación de la ciudad, un equipo creado y financiado por la empresa nacional de reconstrucción del terremoto, coincidía con lo planteado por otros expertos de la administración municipal: el edificio debía demolerse. Esta iniciativa era rechazada por el sindicato de propietarios de locales del mercado, por los usuarios habituales de la galería y por algunos propietarios de inmuebles del sector que suponían que esta demolición implicaría una transformación irreversible de este territorio.

La resistencia de aquellos que se negaban a la demolición se concretó a través de manifestaciones, huelgas y otros mecanismos de presión ilegales, según algunos representantes del gobierno local, como el alcalde de la época que denunció amenazas contra él y su familia, y el jefe de la Oficina de Planeación quien atribuía el intento de secuestro de su hija a las “mafias galería”, constituidas principalmente por traficantes de drogas, por los propietarios de los hoteles y otros actores ilegales. El ambiente era hostil, lo que influyó en que la alcaldía y el consejo municipal no tomaran directamente la decisión política de demoler el edificio central de la galería. Dicha decisión se soportó, como es corriente en el marco de la acción pública urbana, en el discurso de expertos técnicos que le confirieren un halo de legitimidad. Así, el soporte justificatorio de la demolición fue un concepto técnico de arquitectos e ingenieros que, contratados como consultores, diagnosticaron "una patología estructural del edificio".

Vale la pena señalar no obstante, que la narración de un funcionario de planificación de la época en una entrevista, evoca la dificultad para establecer límites entre los intereses políticos, siempre apasionados y la razón, en el contexto de la acción pública urbana. Este funcionario de planificación urbana en Pereira, afirmaba que el primer informe de los expertos indicaba que efectivamente hubo problemas en la estructura del edificio, pero que este podría restaurarse. Un segundo informe, decía que el edificio debía demolerse, algo que favorecía sin duda los intereses de la administración municipal que buscaba resolver los problemas de orden, estética y funcionamiento evidenciados. En este contexto es razonable la afirmación de Bruno Latour (2012), sobre que no existen límites entre los campos de la política y la ciencia, que, en efecto, la 
ciencia invoca a menudo a la política o a otros discursos apasionados y representativos de sistemas de valores que tienen la función de legitimar.

Más allá de la sospecha sobre la manipulación del concepto experto, algo que no se puede constatar, en el relato del antiguo funcionario de la administración vale la pena destacar que éste permitió efectivamente acabar con ese espacio valorado como disfuncional y degradado, es decir, permitió la transformación del centro de la ciudad. Este funcionario afirmaba que en una ciudad intermedia como Pereira, podría suprimirse un espacio como la galería sin ningún problema, dado que ya no era necesario para la vida económica ni social de la ciudad en ese momento de la historia. Su relato refleja dos realidades. De un lado, la mayoría de la población, según una encuesta mencionada por el funcionario y otra realizada por un diario local, mostraba su molestia frente a ese espacio que había perdido su rol de movilizador de pertenencia colectiva alrededor del café, al tiempo que se había tornado peligroso y sucio. La otra realidad, la representaban aquellos que estaban en contra de la demolición, "los sindicatos", las mafias, los sujetos marginalizados e incluso ciertos "antropólogos”, quienes eran vistos, por los encargados de la planificación, como los portadores de una visión tradicional, caótica o en el mejor de los casos romántica de la ciudad, es decir, los aliados de una concepción incompatible con el futuro.

Este tipo de posición, por parte de los administradores municipales de la época, es compartida por personas de la ciudad que tienen el poder de la palabra escrita, como lo muestra el siguiente relato del diario local La Tarde del 14 de abril de 1999:

La ciudad no necesita más galerías. No tiene sentido acabar con un centro de podredumbre social para trasladarlo a otro lugar. Pereira no necesita "galemba" [galería] y si fueren necesarios otros centros de mercadeo como los de la Caja de Compensación Familiar u Olímpicas, ello debe dejarse en iniciativa particular. Para los campesinos productores de artículos perecederos basta fomentar la constitución de una Cooperativa de Productores. No más “galembas”, por Dios, no más. Pereira debe superar esa etapa pueblerina.

En la nueva configuración espacial de la galería no tenían cabida las prácticas de comercio habituales. El futuro implicaba un mercado más sofisticado para los productos agrícolas, así como un proyecto de renovación en el sector y la reubicación de los vendedores y los usuarios estigmatizados. La 
Resolución 198 de 1999 del municipio de Pereira, que ordenaba demoler el edificio principal de la plaza de mercado y otros 20 edificios del sector de la galería, representaba la posibilidad de crear a través de la intervención sobre el espacio, una imagen de la ciudad que fuera coherente con el deseo de acceder a un ideal de ciudad centrado en el futuro. Permitía borrar una materialidad asociada a un pasado que no tiene un valor simbólico, porque según los planificadores, éste no tiene un vínculo con la "modernidad".

En la búsqueda de inteligibilidad del proceso de resignificación del espacio que derivó en la demolición del edificio del mercado central, apelo a la noción de estructuras de sentimiento utilizado por Raymond Williams (2001) para hablar de aquello que permitía construir una concepción de lo rural y de lo urbano en los discursos que ponían en evidencia transformaciones del campo y la ciudad resultado del capitalismo. Williams explica cómo en la Inglaterra de mediados del siglo XVIII las representaciones de algunos textos literarios, revelaban la aparición de sentimientos de melancolía y de pérdida asociados al orden y a una idea de felicidad ligados al campo, en contraposición a los discursos sobre las ciudades que evocaban desorden, pero eran asociados con los ideales de la riqueza del tiempo. Este sentimiento había tomado el lugar de otro en el que la vida rural representaba un lugar idealizado como pacífico y suficiente para la existencia material. En el caso de Pereira, este concepto de estructuras de sentimiento permite comprender las representaciones y los significados socialmente construidos sobre la galería desde la segunda mitad del siglo XX, periodo de producción de significados sobre el espacio que tiene un momento álgido durante la controversia sobre la demolición del edificio central de la plaza de mercado. En el caso de Pereira hay por un lado sentimientos basados en discursos de personas que, a pesar de su peso inexistente en las decisiones urbanas, se negaban a la demolición porque veían en la galería, un lugar donde se podía encontrar una forma esencial de la identidad local y un espacio original y fundador de la ciudad, como lo planteaban algunos escritores locales (García; Marín, 2012). Por otro lado, se puede formular la existencia de una estructura de sentimiento que define los discursos de aquellos que vieron en una transformación urbana, la capacidad de aferrarse a lo contemporáneo, el acceso a las promesas de la modernización. Esta estructura de sentimiento consolidada a lo largo de la crisis de la economía del café, era predominante entre aquellos que tenían una posición dominante y podían tomar decisiones sobre la planificación, basados en principios que reclamaban 
un lugar importante para las tres hermanas de la modernidad: la racionalidad, la objetividad y la utilidad (Latour, 2004).

El triunfo de una estructura de sentimiento que reivindica la modernización, justificó no solamente la demolición de la galería sino la realización de Ciudad Victoria, una operación urbanística de renovación, al tiempo que modificaba las representaciones sobre la ciudad, sus habitantes y las prácticas espaciales. Esta estructura de sentimiento, tenía su correlato en la estructura económica de un municipio que venía mostrando tasas de reducción de participación del sector agrícola en la economía general, altas tasas de desempleo, la quiebra de muchas industrias que se habían sostenido con los capitales asociados al café y la definición de una serie de políticas económicas que buscaban una reconversión de la economía local, sin mucha claridad.

\section{La planificación de la rehabilitación simbólica}

El decreto donde se aprueba la principal herramienta de planificación urbanística de la ciudad de Pereira (Plan de Ordenamiento Territorial -Porte) declara en el año 2000 la intención de convertir al "municipio en un centro de negocios y de servicios del occidente colombiano, a través de la consolidación de una plataforma territorial competitiva que haga posible el desarrollo humano sostenible para sus habitantes” (Consejo Municipal de Pereira, 2000, p. 8). Además, se proponía en dicho documento "recuperar a nivel urbanístico el centro tradicional de la ciudad, para evitar el proceso de degradación y convertirlo en el gran centro metropolitano" (Consejo Municipal de Pereira, 2000, p. 8).

Este documento de planificación se inscribe en un "ambiente ideológico" (Althabe, 1993, p. 16) organizado en torno al supuesto que la modernización de la economía local va a focalizarse en actividades terciarias que giren en torno a un tipo de comercio distanciado del intercambio de bienes rurales. Otro supuesto es que el centro de la ciudad debe ser transformado para reafirmar el desarrollo de la actividad comercial, pero también para cambiar la imagen de la ciudad en función de mostrarse competitiva a nivel regional (Vallejo, 2010).

Concretar una operación urbanística era finalmente viable gracias a la demolición de la galería, a la capitalización del municipio derivada de privatización del 50\% de las acciones de la empresa de telecomunicaciones y a la generalización de nuevas herramientas jurídicas de planificación (la Ley 3988 
de ordenamiento territorial de 1997). A pesar del contexto favorable y de la voluntad política del gobierno local que inició su periodo en 2001, seguía siendo problemático el manejo de la situación de los habitantes de calle y de los practicantes de este espacio que, aunque ya no era un mercado, seguía siendo apropiado por éstos. Era problemático igualmente el control de actividades ilegales como "el microtráfico y el consumo de drogas en las llamadas 'ollas' del sector” (Marulanda, 2013, p. 76) y de otras actividades delictivas o estigmatizadas socialmente. La galería se había convertido en un espacio abandonado a la delincuencia, caracterizado por una "ausencia de gobernabilidad” (Rojas et al., 2000, p. 89).

\section{La restitución del orden y de la función}

Mientras que los discursos de los técnicos de planificación para describir el estado del espacio de la antigua galería descansa sobre nociones como “degradación espacial y material”, el discurso de los representantes políticos presenta otro registro. La alcaldesa municipal durante el periodo 2001-2003, manifestaba de manera recurrente durante una entrevista realizada en 2014, su preocupación por la suciedad del espacio, de las calles y de los habitantes:

[...] yo llego a la alcaldía y lo primero que tengo que decir es barramos, y ordenar a los empleados [de la administración municipal] quitar un intercambiador de basuras que había en el sector, o demoler un comercio de artículos de segunda mano, "rancho de lata", que reunía indigentes [y otras personas marginalizadas $][\ldots]$.

Esta solución implicaba además emprender un conjunto de acciones que se inscriben en una preocupación higiénica y estética, como promover que las fachadas de las destartaladas viviendas del sector fueran pintadas de blanco. Otra de las medidas cuestionadas era obligar a darse una ducha a los habitantes de la calle, luego de haberlos acogido en centros de rehabilitación de drogas, donde además eran peluqueados en contra de su voluntad (Perdomo; Restrepo; Vásquez, 2009). Estas acciones públicas y otras también de naturaleza represiva emprendidas para “recuperar” el espacio del antiguo mercado, han sido asociadas públicamente por algunos autores (Álvarez, 2010; Perdomo; Restrepo; Vásquez, 2009) con una práctica abominable de 
asesinatos de indigentes o de delincuentes cometidos por desconocidos, "limpieza social”, la cual tuvo lugar en el centro de Pereira sobre todo durante el tiempo de ejecución, preparación y realización de la operación urbanística. El vínculo entre la acción pública y las prácticas de "limpieza social”, no ha sido probado, pero los rumores constantes sugieren que ciertos actores de la ciudad tenían gran determinación por cambiar a todo precio ese sector de la ciudad.

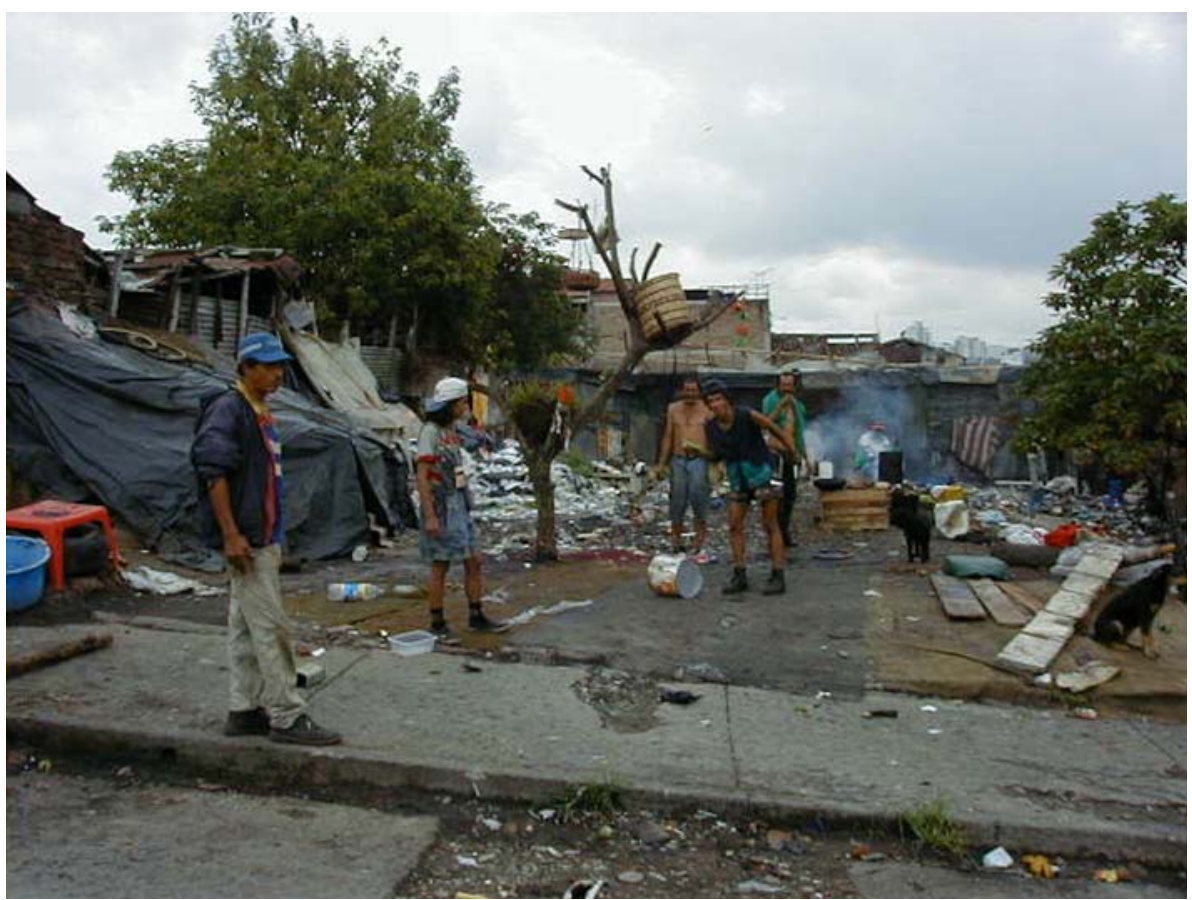

Figura 2. El sector de la galería en 1999 (fuente: Alcaldía de Pereira).

Otras acciones públicas fueron ejecutadas para liberar este espacio de actores que no se acoplaban a la "ciudad ideal", soportada por el ambiente ideológico que sustentaría el cambio. Se puede señalar, por ejemplo, la relocalización de los habitantes de los inquilinatos, muchos de los cuales fueron enviados a viviendas ubicadas en la periferia de la ciudad, la negociación con 
los propietarios o la persecución a los vendedores ambulantes que siguieron frecuentando el sector, quienes se convirtieron en "desviados de la norma" (Ortíz, 2012).

El conjunto de acciones públicas emprendidas para transformar la imagen asociada a la galería, conjuga lógicas de los ámbitos político, económico y cultural. La recuperación del centro tradicional y del espacio público fue a la vez asumida como un asunto de orden moral y cósmico del espacio y como una manera de responder, de acuerdo con el relato de una funcionaria de planificación de alto rango de la época (Vallejo, 2010, p. 30), a la necesidad de inversiones para una zona estratégica de la ciudad que se estaba viendo afectada por problemas de devaluación del suelo y por un nulo atractivo para los inversionistas.

La estrategia para satisfacer a los inversionistas guardaba una similitud con las medidas puestas en funcionamiento por el urbanismo europeo durante el siglo XIX y principios del XX. Es decir, un urbanismo centrado en una perspectiva higienista, moralista y racionalista del espacio (Monnet, 1993). En la versión higienista, moralista y racionalista local las prostitutas, los drogadictos y los indigentes son pensados desde consideraciones atinentes a la salud o a la moral, las cuales no son concordantes con una visión del mundo que privilegia el orden, la apariencia y la función de la ciudad (y de sus habitantes), como principio para la atracción de inversionistas. Otros practicantes del espacio como los vendedores ambulantes o los campesinos que persistían, eran considerados como productores de caos y de una imagen estética también distante de los principios de orden del espacio urbano (Herzfeld, 2009; Limón López, 2012), construido en el marco del “ambiente ideológico” que promueve la modernización de la ciudad a través de la inversión privada.

Si bien la intervención sobre "lo social” había comenzado después del sismo de 1999 con recursos nacionales destinados a la reconstrucción, la alcaldía orientó presupuesto para resolver la “problemática social” de la galería. Antes de iniciar el plan parcial de renovación urbana Ciudad Victoria en 2002, el municipio había invertido una cuantiosa cifra en el marco de un programa llamado Recuperación integral de la zona de la antigua galería (Vallejo, 2010). Más allá de las intenciones de las ONG que participaron como ejecutoras, el interés de la alcaldía no era solamente resolver los problemas de una población “abandonada por el Estado” durante un largo periodo, sino limpiar y ordenar el espacio previendo las inversiones (Ortíz, 2012). La anterior afirmación es acorde con el relato de la alcaldesa de la época: 
Supe que el Éxito se quería ir para Armenia, antes de yo posesionarme como alcaldesa, Fernando Montoya me busco, [y me dijo] doctora, yo quiero que el Éxito se venga para acá y listo, porque también tengo una posibilidad en Armenia, [los dirigentes del Éxito] salieron con otra posibilidad, y entonces empieza como a madurar la idea, [después de enterarme de esto] empecé a limpiar, y empecé a organizar [la ciudad], con nada más.

Estas acciones de limpieza de este "espacio obsoleto" en el cual las actividades económicas habían perdido velocidad, el espacio físico estaba degradado (Morin, 1987, p. 77) y la población se había pauperizado, fueron claves para demostrar a los investigadores que sus capitales eran objeto de inversión en una en proceso de recuperación. Sin embargo, dichas acciones se prolongaron durante una parte del tiempo de la ejecución del proyecto, sobre todo, durante el periodo de construcción de los principales edificios, espacios públicos y equipamientos urbanos.

\section{Nacimiento de un nuevo espacio y la refundación de la ciudad}

El Taller de planificación de la ciudad había propuesto durante el año 2000 una renovación urbana por el sector de la antigua galería centrado en la construcción de un centro cultural y la creación de espacio público. Sin embargo la administración municipal de 2001 propuso una intervención sobre el espacio del centro de la ciudad que era coherente con los objetivos del Plan de Ordenamiento Territorial, pero sobre todo, que apuntaban al cumplimiento de objetivos a nivel económico y a la idea de construir una imagen de ciudad competitiva. En consecuencia se propuso un plan de renovación urbana que privilegiara la participación de capital privado, lo cual iba a tener consecuencias en la disposición del espacio. La decisión fue tomada en parte, según lo relataba la alcaldesa, con base en el análisis de proyectos similares en Colombia, de donde se dedujo que era fundamental garantizar dicha participación privada con el fin de incorporar en la nueva configuración espacial algunas estructuras que resultaran atractivas para una "otro tipo de usuarios".

Así se crea el decreto que otorga existencia al Plan parcial de renovación urbana Ciudad Victoria, que tenía por objetivo principal

[...] promover acciones integrales (políticas, sociales, físicas, económicas y ambiéntales) que detengan el deterioro y promuevan la renovación urbana, con el

Horizontes Antropológicos, Porto Alegre, ano 22, n. 45, p. 249-278, jan./jun. 2016 
fin de concederle al centro tradicional su dinámica económica y funcionalidad, recuperando el patrimonio arquitectónico y su carácter de polo comercial atractivo para la ciudad. (Pereira, 2002, p. 3).

La delimitación del área de intervención de 9,96 hectáreas es decir el $17 \%$ del centro de la ciudad, obedeció, según la directora de planificación de la época a criterios donde: "la intervención debía hacerse como un proyecto de inversión público-privado, como una empresa y no solamente como un ejercicio de planificación” (Vallejo, 2010, p. 234). En virtud de lo anterior, la alcaldía garantizó la participación de dos socios claves en el proyecto: un grupo económico con capital colombiano y francés para que adelantara la construcción de un hipermercado y un grupo de capital colombiano, promotor inmobiliario y constructor que se comprometió en la construcción de un gran centro comercial regional. Las estructuras resultantes de esta gestión comercial del proyecto resultaron esenciales para cumplir con la finalidad de desarrollar económicamente este sector de la ciudad.

Además de estas áreas el proyecto comprende también un edificio de uso público, un centro cultural, financiado por la administración de la ciudad, otro edificio de financiación y de uso público y privado, y dos sectores importantes con equipamiento urbano, dedicados a espacio público: una plaza que funge de ágora de la ciudad y un modesto parque lineal de 200 metros. El primer espacio es usado cotidianamente como sitio de tránsito entre el centro comercial y la tienda de grandes superficies, y el segundo espacio es en parte una extensión verde del centro comercial, en parte, un lugar apropiado por algunos vendedores ambulantes que resisten a la represión de las autoridades de la municipalidad.

De manera contradictoria a lo formulado por la administración municipal que hablaba de una “ciudad compacta” y de la "densificación” del centro de la ciudad (Vallejo, 2010), el medio idóneo para lograr esto, la incorporación de un área de vivienda en el proyecto, no se concretó. Las causas resumidas fueron los problemas de imagen comercial de un proyecto implantado en una zona sobre la que recaía un penoso estigma y "la falta de estrategias por parte de la administración municipal para evitar la especulación con el valor de los suelos del sector” (Ortíz, 2012, p. 138-139, traducción mía). Finalmente los precios se elevaron lo suficiente como para hacer inviable una iniciativa que permitiera darle vida real al barrio. Así las cosas, las viviendas antiguas fueron demolidas para poner en funcionamiento una política en la que los antiguos habitantes 
fueron desplazados para distanciarse del nuevo proyecto de ciudad, pero no se garantizó el arribo de otros habitantes, sólo de sitios de actividad económica.

Si bien la proporción de espacio público del proyecto es considerable y el centro cultural ofrece una finalidad pública, el conjunto de la operación obedeció al interés por convertirlo en un espacio comercial, pero de un tipo de comercio específico, un comercio de gran formato, de centros comerciales y de grandes tiendas, algo mucho más espectacular que un conjunto de modestas tiendas o un conjunto de edificios de vivienda.

El 13 de diciembre de 2004, en el marco de una celebración de fin año, luego de una importante campaña publicitaria regional, tuvo lugar el acto fundacional de la renovación urbana: abrió sus puertas el centro comercial. La inauguración del otro nodo de esta configuración espacial, la tienda de gran superficie, fue el 17 agosto de 2005, en el marco de la fiesta de aniversario de la ciudad, y constituyó otro evento que funcionó para construir ritualmente los "vínculos simbólicos en el territorio, su espacio construido y sus propias representaciones del universo" (Segaud, 2007, p. 107, traducción mía). Estas representaciones ritualizadas en un tiempo social muy significativo, concedían un lugar central a este tipo de comercio y en general celebraba la transformación espacial y, claro está, sociocultural.

\section{Un nuevo auge: la ciudad de los centros comerciales}

Los detractores de la operación en su conjunto son numerosos en la ciudad. Un buen número de críticas realizadas sobre todo por especialistas científicos sociales locales o por representantes de ONG, versan sobre el manejo de la problemática social de la antigua galería. Otras críticas de arquitectos, planificadores o urbanistas, confluyen en tópicos sobre el diseño de los edificios, del equipamiento urbano o la disposición del espacio público. Una crítica que se convirtió en un lugar común, como advertí a lo largo de mi trabajo de campo, es que la administración municipal interrumpió el flujo de una calle, la carrera 11, para permitir la construcción del centro comercial y la tienda de grandes superficies.

Los detractores que centraban sus críticas en este hecho, lo convertían en la representación más evidente de que la administración había realizado muchas concesiones a los inversionistas privados, sacrificando infraestructuras públicas con el fin de construir el centro comercial y la tienda de gran superficie. Ante los cuestionamientos, el gobierno de la época se defendía señalando la 
compensación con espacio público y afirmaba que ésta aportaba a la movilidad peatonal urbana. Sin embargo eran tal vez los argumentos de orden económico y social los más contundentes, los que lograron que las críticas no trascendieran a otros sectores. Como lo reiteraban los diarios locales, la presencia del centro comercial y de la tienda produjeron una transformación inusitada de la economía local y sobre todo lograron desaparecer del centro de la ciudad la delincuencia, las muestras de miseria, la inmoralidad, la insalubridad y la suciedad.

Dicha percepción centrada en el éxito estético y funcional de la transformación del centro de la ciudad, le atribuía la capacidad de haber operado el nacimiento de otro tipo de comercio, ligado a la posibilidad de desarrollar el turismo urbano. Con escasa nostalgia, al menos para las clases dominantes, quedo atrás el pasado exitoso del café y el reciente momento de crisis. El presente recibía el florecimiento de un comercio de centros comerciales y de hipermercados.

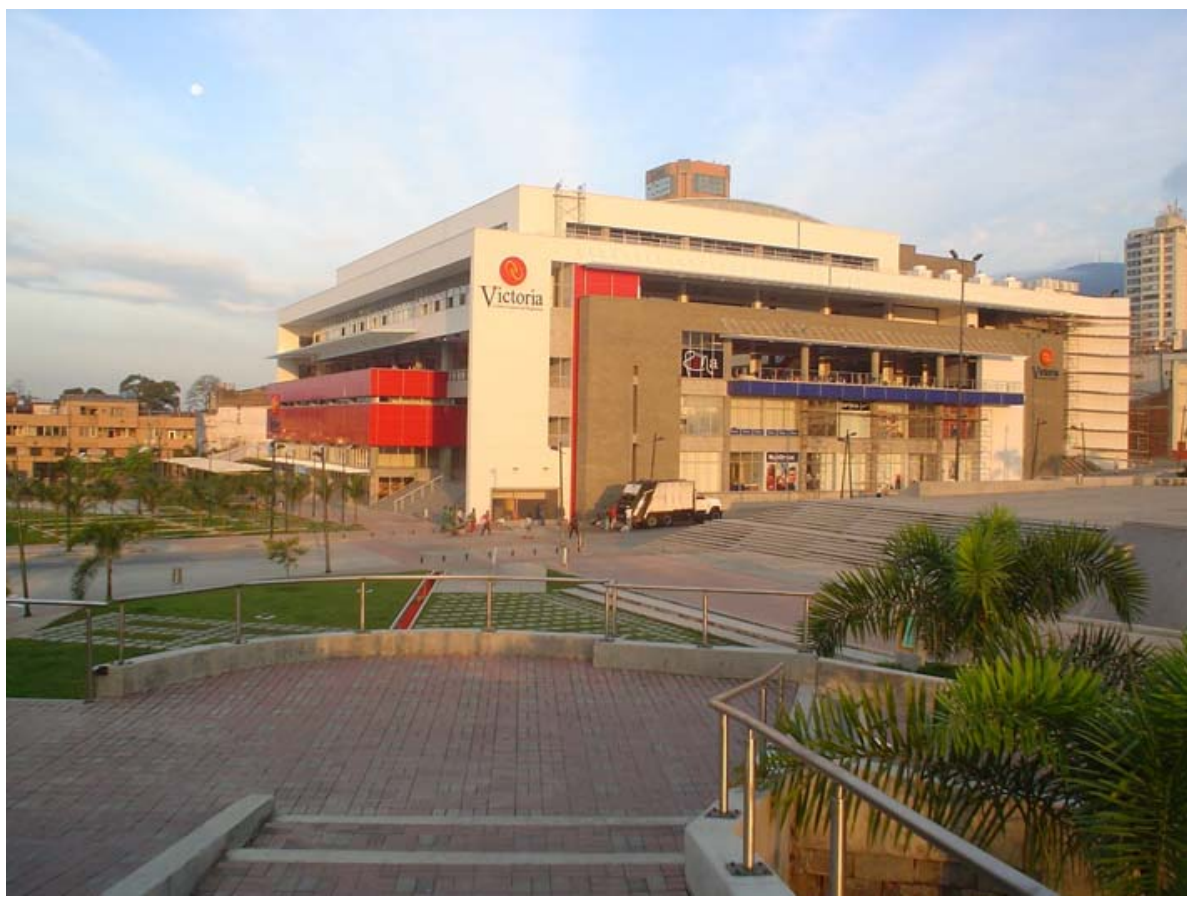

Figura 3. Ciudad Victoria 2004 (fuente: Alcaldía de Pereira). 
Es necesario señalar, sin embargo, que este centro comercial y la tienda de gran superficie no fueron las iniciativas pioneras de su género en la ciudad. En 1981 abrió sus puerta el primer centro comercial de Pereira, por iniciativa de un empresario local que ha tenido problemas con la justicia por narcotráfico (Bloque..., 1997). Este hecho no es anecdótico, el narcotráfico era reconocido como una actividad arraigada en la ciudad desde los años 1980 (Gómez Navas, 2009; Salazar; Frasser, 2013), sin embargo, después de los años 1990, como le afirmaba un jefe de la policía nacional: "Pereira se convirtió en el ‘paraíso' de los narcotraficantes del Valle del Cauca” (Bloque..., 1997).

En Colombia "la narcoeconomía influenció no solamente el comportamiento de la economía en general sino, entre otros, el dinamismo intrínseco del sector de la construcción” (Giraldo, 1990 apud Castelli, 1999, p. 254, traducción mía). A pesar de esto, la relación que pretendo establecer entre esta actividad económica y la refundación de la ciudad a través de la operación urbanística hasta aquí presentada, no reposa sobre la posible incidencia del dinero del narcotráfico en su construcción. Ésta apunta más bien al hecho de que las actividades en torno al narcotráfico han generado un conjunto de condiciones económicas, sociales y culturales que favorecen la realización de acciones públicas a nivel urbanístico que promueven la construcción de este tipo de comercio. Efectivamente la afluencia de capitales del narcotráfico a Pereira ha contribuido con el desarrollo de la actividad comercial, pero más allá de esta constatación, los centros comerciales se convirtieron en lugares privilegiados para la adquisición del tipo de bienes de consumo suntuosos que son de predilección de estos sectores de la población atraídos por el lujo y la ostentación. Además, los centros comerciales se convirtieron en lugares claves para otros sectores de la población no relacionados necesariamente con el narcotráfico, pero que han visto en la lógica de ostentación -que implica estos circuitos de comercio- un medio para realizar sus deseos de elevación de estatus (Baudrillard, 1997) y una manera de "igualar o imitar" a través del consumo conspicuo (Veblen, 2002) a los representantes del éxito social en la ciudad y en la región.

El auge de estas estructuras comerciales en Pereira, que comenzó en los años 1990, se consolidó en los años 2000, como consecuencia de la puesta en funcionamiento de Ciudad Victoria. Según la Federación Nacional de Comerciantes, hacia el año 2012, "mientras que la media nacional de metros cuadrados de centro comercial por cada 100 habitantes es de 12, en Pereira es de 25” (¿Hay mercado..., 2012). 
El periodo de expansión de los centros comerciales, coincidió también con el crecimiento de las tasas de emigración al extranjero, otra actividad que dinamizó la declinante economía resultado de la crisis del café (Cepeda Emiliani, 2011). El Departamento de Risaralda, contaba con la primera cantidad de población emigrante del país, 9,1\%, y Pereira, su capital, tenía la segunda tasa más alta del departamento, 10,1\% (Cepeda Emiliani, 2011). Para este periodo las transferencias de dinero constituían la tercera fuente del PIB nacional (Khoudour-Castéras, 2007), y a nivel local, Pereira presentaba la cifra más alta en transferencias de dinero por habitante (Cepeda Emiliani, 2011). Además de los usos funcionales de las transferencias de dinero, los beneficiarios de éstas le asignaban un alto valor social y simbólico porque les permitía acceder a bienes de prestigio y a las prácticas de consumo y ostentación ligadas a los centros comerciales de la ciudad (Hernández Pulgarín, 2012).

De esta manera, la ciudad y los ciudadanos en su nueva versión de consumidores encontraron en el desarrollo comercial un medio para hacer evidentes los símbolos de progreso, colectivos et individuales. Para la ciudad, esto se traduce en el acto de transformar y refundar su centro, a través de una acción pública que permitía desarrollar el comercio a gran escala, en el marco de particularidades históricas, económicas y sociales. Dichas condiciones de diversa naturaleza y procedentes de fenómenos provenientes de otras escalas territoriales, fueron codificadas culturalmente, insertadas en lo que podría llamarse la matriz cultural local, lo que dotaría localmente de sentido a los cambios inscritos sobre el espacio y en la dinámica social de la ciudad, como diría Sahlins (2001), remitiría su asimilación, los indigenizaría.

\section{Comentarios finales}

Las acciones urbanísticas que implicaron la demolición de edificios, el destierro de la población marginalizada y estigmatizada de la galería, o la construcción de la nueva configuración comercial del centro, reflejan la relación inextricable que existe entre las transformaciones económicas y la manera cómo éstas son codificadas culturalmente, partiendo siempre de un correlato espacial.

En el caso analizado, durante un periodo de auge de una economía rural asociada al café, el sector de la galería encarnaba un conjunto de valores 
empleados como referentes para la identidad local, lo cual hacía que al margen de problemas percibidos como la degradación física, fuera un espacio que movilizaba sentimientos favorables. Frente a las transformaciones del sistema económico, por causas globales y locales, la estructura de sentimiento que orienta la valoración de este espacio cambia. Ese momento marca el surgimiento de una estructura de sentimiento favorable a formas de modernización y de progreso, que se objetivan en la adopción de nuevas prácticas sociales, centradas en el consumo conspicuo, pero también en la necesidad de generar un nuevo espacio acorde con lo que es estimado, según la nueva estructura de sentimiento.

Así pues, un espacio que se transforma urbanísticamente en la actualidad, lo hace porque en su gestión puntual se movilizan intereses económicos y políticos que atienden a ideologías economicistas como se suele analizar clásicamente. Pero también se transforma porque hay factores culturales, estructuras que organizan el mundo cultural, las cuales se actualizan y dan sentido a las acciones conscientes o inconscientes que se emprenden para convertir un espacio en decadente o emblemático.

\section{Referencias}

ALTHABE, G. Promotion symbolique et logiques sociales. In: ALTHABE, G.; LEGÉ, B.; SELIM, M. Urbanisme et réhabilitation symbolique: Ivry, Bologne et Amiens. Paris: L’Harmattan, 1993. p. 1-14.

ÁLVAREZ, J. Tiros de gracia. Breve historia de la limpieza social en Pereira. El Malpensante, Bogotá, n. 112, p. 34-39, sept. 2010.

APRILE-GNISET, J. La ciudad colombiana: siglo XIX y siglo XX. Bogotá: Banco Popular, 1992.

ARANGO, O. Pereira, años 90's. Pereira: Universidad Tecnológica de Pereira, 2000.

BAQUERO, D. Las plazas de mercado como catalizadores urbanos. Bogotá: Universidad Nacional de Colombia, 2011. 
BAUDRILLARD, J. La sociedad de consumo, sus mitos, sus estructuras. Barcelona: Anagrama, 1997.

BÉAL, V.; ROUSSEAU, M. Néolibéraliser la ville fordiste. Métropoles, n. 4, p. 160-202, 2008.

BLOCH, M. Les usages de l'argent. Terrain, Paris, n. 23, p. 5-10, 1994.

BLOQUE incautó arsenal del industrial Alcides Arévalo. El Tiempo, Bogotá, p. 7, 17 ene. 1997.

CASTELLI, B. Les impacts urbains du recyclage de l'argent de la drogue dans la région des Andes. Revue Tiers Monde, Paris, n. 158, p. 251-270, 1999.

CASTRO CARVAJAL, B. Aspectos de la vida diaria en las ciudades republicanas. Credencial Historia, Bogotá, n. 55, p. 12-13, 1994.

CEPEDA EMILIANI, L. La economía de Risaralda después del café: ¿Hacia dónde va? Documentos de trabajo sobre economía regional del Banco de la República, Bogotá, n. 153, p. 1-38, 2011.

CONSEJO MUNICIPAL DE PEREIRA. Plan de Ordenamiento Territorial, Porte Pereira. Pereira: Imprenta Municipal, 2000.

DE LA PRADELLE, M. Les vendredis de Carpentras: faire son marché en Provence ou ailleurs. Paris: Fayard, 1996.

DUMONT, L. Homo cequalis I: genèse et épanouissement de l’idéologie économique. Paris: Gallimard, 1978.

ESCOBAR, A. Economic and space of modernity: tales of market, production and labour. Cultural Studies, Abingdon, v. 19, n. 2, p. 139-175, 2010.

ESTEBAN, I. El efecto Guggenheim, del espacio basura al ornamento. Barcelona: Anagrama, 2007.

FASSIN, D.; EIDELIMAN, J.-S. Économies morales contemporaines. Paris: La Découverte, 2012. 
GARCÍA, C.; MARÍN, E. Memoria virtual portal literario y cultural del Eje Cafetero. Pereira: Universidad Tecnológica de Pereira, 2012.

GAVIRIA, M.; SIERRA, H. Pobreza, inserción precaria y economía popular en Risaralda. Pereira: Eumedonet, 2006.

GIRALDO, T. Instrumentos de planeación y gestión para intervenir un área céntrica deteriorada: caso: sector antigua galería de Pereira. 2003. Tesis (Maestría en Hábitat)-Universidad Nacional de Colombia, Manizales, 2003.

GÓMEZ NAVAS, D. Democracia y narcotráfico en Colombia. Ciudad Pazando, Bogotá, v. 2, n. 1, p. 89-112, 2009.

GRAEBER, D. Toward an anthropological theory of value: the false coin of our own dreams. New York: Palgrave, 2001.

HACKWORTH, J. The neoliberal city: governance, ideology, and development in American urbanism. Ithaca: Cornell University Press, 2006.

HARVEY, D. From managerialism to entrepreneurialism: the transformation in urban governance in late capitalism. Geografiska Annaler: Series B: Human Geography, Hoboken, v. 71, n. 1, p. 3-17, 1989.

¿HAY MERCADO para tantos centros comerciales en el Eje Cafetero?. El Tiempo, Bogotá, p. 12, 8 oct. 2012.

HERNÁNDEZ PULGARÍN, G. Verracos verdaderos o la segregación de alteridades en la representación de la identidad cultural de los paisas. In: NATES, B. Evocaciones míticas e identidades actualizadas. Manizales: Universidad de Caldas, 2006. p. 63-80.

HERNÁNDEZ PULGARÍN, G. Cuatro aportes desde la antropología para comprender la emigración. Universitas Humanística, Bogotá, n. 74, p. 35-56, 2012.

HERZFELD, M. The social production of indifference: exploring the symbolic roots of Western bureaucracy. Chicago: The University of Chicago Press, 1993. 
HERZFELD, M. Evicted from eternity: the restructuring of Modern Rome. Chicago: University Of Chicago Press, 2009.

KHOUDOUR-CASTÉRAS, D. Migraciones internacionales y desarrollo: el impacto socioeconómico de las remesas en Colombia. Revista de la CEPAL, Santiago de Chile, n. 92, p. 143-161, 2007.

LATOUR, B. Le rappel de la modernité. Approches anthropologiques. ethnographiques.org, n. 6, 2004. Disponible en: <http://www.ethnographiques. org/2004/Latour>. Acceso el: 13 abr. 2013.

LATOUR, B. Enqueter sur les modes d'existence: nne anthropologie des modernes. Paris: La Découverte, 2012.

LIMÓN LÓPEZ, P. Producción jurídica e imaginación global: cartografías urbanas a través de la ley en Barcelona. Geopolítica(s), Madrid, v. 3, n. 1, p. 117-135, 2012.

LINS RIBEIRO, G. Power, networks and ideology of development. Tabula Rasa, Bogotá, n. 6, p. 173-193, 2007.

LOTERO CONTRERAS, J. Apertura económica y desarrollo industrial en las áreas metropolitanas de Colombia. Eure, Santiago de Chile, v. 24, n. 72, p. 95-117, 1998.

LOW, S. Cerrando y reabriendo el espacio público en la ciudad latinoamericana. Cuadernos de Antropología Social, Buenos Aires, n. 30, p. 17-38, 2009.

MARULANDA, L. La liminalidad de las “ollas”: relaciones entre la ilegalidad y la legalidad en el mercado de drogas ilícitas de la ciudad de Pereira. Virajes: Revista de Antropología y Sociología, Manizales, v. 15, n. 2, p. 73-100, 2013.

MEJÍA, W. Llegadas, salidas y retornos a la “Ciudad sin puertas”. Un vistazo a Pereira desde la perspectiva migratoria. In: DURÁN, M. Un hecho, tres miradas. Pereira: Fusionarte, 2011. p. 13-17.

MONNET, J. La ville et son double: la parabole de Mexico. Paris: Nathan, 1993.

Horizontes Antropológicos, Porto Alegre, ano 22, n. 45, p. 249-278, jan./jun. 2016 
MONNET, J. Les dimensions symboliques de la centralité. Cahiers de géographie du Québec, Montréal, v. 44, n. 123, p. 399-418, 2000.

MONTOYA, J. El sistema urbano colombiano frente a la globalización: reestructuración económica y cambio regional. Cuadernos de Vivienda y Urbanismo, Bogotá, v. 6, n. 12, p. 302-320, 2013.

MORIN, R. Réanimation urbaine et pouvoir local: les stratégies des municipalités de Montréal, Sherbrooke et Grenoble en quartiers anciens. Paris: PUQ, 1987.

OKONGWU, A. The anthropology of public policy: shifting terrains. Annual Review of Anthropology, Palo Alto, n. 29, p. 107-124, 2000.

ORTÍZ, C. Bargaining space: deal-making strategies for largescale renewal projects in Colombian cities. 2012. Thesis (Ph D Urban Planning and Policy)University of Illinois at Chicago, Chicago, 2012.

PECK, J.; THEODORE, N.; BRENNER, N. Neoliberal urbanism: models, moments, mutation. SAIS Review, Washington DC, v. 29, n. 1, p. 49-66, 2009.

PERDOMO, J.; RESTREPO, C.; VÁSQUEZ, Á. Proyecto de renovación urbana: una lectura desde la intolerancia social. Pereira: Fundación Universitaria del Área Andina-Pereira, 2009.

PEREIRA(Alcaldía). Decreto 1301 de 2002. Pereira: Imprenta Municipal, 2002.

POLANYI, K. La grande transformation: aux origines politiques et économiques de notre temps. Paris: Gallimard, 1983.

RAMÍREZ, J.; TARAZONA, Á. Sociabilidades, visiones de ciudad y cultura ciudadana. El civismo en Pereira. Revista Historia de la Educación Latinoamericana, Tunja, n. 9, p. 181-202, 2007.

RIVERA, A. Proceso de urbanización y agentes urbanos en Pereira, Colombia: desigualdad social, fragmentación espacial y conflicto ambiental, 1990-2012. 2013. Tesis (Doctorado en Geografía)-Universitat de Barcelona, Barcelona, 2013. 
ROJAS, H. et al. Lineamientos generales para el acompañamiento y gestión social de los proyectos formulados por el Taller de Gestión Urbana. Pereira: Fundación Vida y Futuro, 2000.

SAHLINS, M. Cultura y razón práctica. Barcelona: Gedisa, 1997.

SAHLINS, M. Dos o tres cosas que se acerca del concepto de cultura. Revista Colombiana de Antropología, Bogotá, n. 37, p. 290-327, 2001.

SALAZAR, B.; FRASSER, C. Menos cocaína, más violencia. Revista de Economía Institucional, Bogotá, v. 15, n. 29, p. 327-334, 2013.

SEGAUD, M. Anthropologie de l'espace: habiter, fonder, distribuer, transformer. Paris: Armand Colin, 2007.

TOCANCIPÁ, J. El juego político de las representaciones. Análisis antropológico de la identidad cafetera nacional en contextos de crisis. Antípoda, Bogotá, n. 10, p. 111-136, 2010.

VALLEJO, A. Ciudad Victoria. In: ARZAYÚS, P.; GARCÍA, M. Las ciudades del mañana: gestión del suelo urbano en Colombia. Washington DC: BID, 2010. p. 225-258.

VAN CRIEKINGEN, M. Urbanisme néoliberale et politiques de gentrification: main basse sur le quartier de la gare TGV a Bruxelles. Géo-Regards, Neuchâtel, n. 1, p. 111-125, 2008.

VEBLEN, T. Teoría de la clase ociosa. Madrid: Fondo de Cultura Económica de España, 2002.

WEDEL, J.; FELDMAN, G. Why an anthropology of public policy? Anthropology Today, London, v. 21, n. 1, p. 1-2, 2005.

WILLIAMS, R. El campo y la ciudad. Buenos Aires: Paidós, 2001. 